\title{
Impact of Sustainable Product Design on Elderly Ergonomics
}

\section{Tris KEE* and Alex KING}

Faculty of Design and Environment, Technological and Higher Education Institute of Hong Kong, Hong Kong

*Corresponding author: Tris Kee, Associate Professor, Faculty of Design and Environment, Technological and Higher Education Institute of Hong Kong, 133 Shing

\begin{tabular}{c} 
Research Article \\
Volume 2 Issue 4 \\
Received Date: July 06, 2018 \\
Published Date: August 02, 2018 \\
DOI: $10.23880 /$ eoij-16000168 \\
\hline
\end{tabular}

Tai Road, Chai Wan, Hong Kong, Tel: (852) 38908307; Email: triskee@vtc.edu.hk

\section{Abstract}

With an unprecedented increase in the ageing population in the global context, 47 million people are currently living with dementia worldwide according to the World Health Organisation Report - Dementia: A Public Health Priority (2017). Although there is a number of research that contributed to the design of health- and-safety products for people with dementia, co-designed elderly health care products or research are scarce. This paper aims to fill the gap in research by, firstly, co-designing and developing a series of ten sets of elderly ergonomics board games to delay the deterioration in cognitive function, behavioral changes and functional limitations of elderly with dementia; and secondly, examining the impact of the elderly ergonomics products on their six recognized physical and cognitive domains; namely memory, language, recognition, visuospatial function, numeracy and attention. By utilizing qualitative research methodology, this research employed desktop study, observation, semi-structured face-to-face interviews, and focus groups discussions to understand the experiences of this set of co-designed products on the impact of health development on the ageing population. The paper provides an insight into both psychological and health impact and development of a specially designed health care product design on the dementia cohort in Hong Kong aged 65 to 95 . The findings of this research can make significant contributions to the scholarly understanding of the enhancement of elderly's health and living environment since Hong Kong is confronted with a severe ageing demography.

Keywords: Codesign; Elderly Ergonomics; Product Design; Ageing Population; Health Care Sustainability

\section{Introduction}

According to the World Health Organisation Report in April 2017, there is an estimated 47 million of population living with dementia in the world and the number is projected to soar a further 60 percent in 2030 [1]. Among the Asian population, the estimated number of people having dementia is expected to reach 20.8 million by 2030 in mainland China, Hong Kong and Taiwan [2]. A metaanalysis study conducted by Backman, et al. [3] found that elderly's cognitive functions started to decline several years before dementia onset, and the preclinical phase tended to be shorter for late-onset dementia (aged $\geq 75$ ) than for early-onset (aged $<75$ ). A recent survey found that the average life expectancy of Hong Kong people is the longest worldwide with an average life spans of 87.32 


\section{Ergonomics International Journal}

years and 81.24 years for Hong Kong women and men respectively [4]. These figures suggested that there is an impending cognitive deterioration among the steep increase of Hong Kong ageing population. However, most of the elderly research on dementia and industrial design ergonomics were often grounded in Western context or Western population cohorts; research specific to Hong Kong ageing population and design ergonomics remains lacking [5-9]. Since dementia is considered to be one of the most significant issues among age-related health problems, people with dementia should be more involved in participatory design and ergonomics research to enhance the outcome for the end users $[10,11]$. Although existing health and ergonomic products have utilized training games to study cognitive deterioration, it was discovered that dementia elderly with cognitive, emotional and behavioral issues could thwart the communication between people with dementia and members of the design team $[6,12,13]$. In order to enhance the participation of stakeholders in co-design projects, Smeenk, Sturm, and Eggen [14] developed a three-step design framework to overcome the difficulties of working with elderly with dementia. This paper aims to build on this established philosophy by investigating the societal, design and health aspirations of Hong Kong elderly with dementia by applying the framework of empathic co-design, and the psychological therapeutic approach of reminiscence to develop a series of ten sets of ergonomic training board games that aims to delay the deterioration of cognitive functions of elderly with dementia in six domains; namely memory, language, recognition, visuospatial function, numeracy and attention [14,15]. This paper will illustrate the process between designers, academics, health professionals and elderly through observation and semi-structured interviews. By employing qualitative method, this paper first identifies the needs and everyday challenges of elderly with dementia to provide a framework that will be expanded and explained the later focus groups interviews. Thematic analysis will be applied to demonstrate how the co-design process enhances participatory design development to achieve a sustainable and impactful outcome in improving health care and ergonomic products for the ageing population in Hong Kong.

\section{The Nature of Dementia and Ergonomic Therapy}

Dementia is a broad term of neurodegenerative disorder that negatively and gradually affects individuals' cognitive abilities [16]. It may occur when the brain is affected by some specific diseases, such as Alzheimer's disease (AD) or a series of strokes causing confusion, speech problems and progressive memory loss [17]. The most common types of dementia include $A D$, vascular dementia, dementia with Lewy bodies and front temporal dementia. People with mid cognitive impairment (MCI) are more likely to have problem of reasoning, memory and planning, however, they are still able to carry out normal daily activities. The hallmark of the progressive deterioration in cognitive function is not considered to be part of normal ageing. In an ageing population, dementia is considered having such a profound impact on the society those health care expenditures on elderly with dementia is the highest among those with other chronic diseases [18]. Since the onset of cognitive deficits is rather gradual in the early stage of dementia among elderly, caregivers usually ignore the symptom and attribute it to the general process of ageing until symptoms have become severe [13]. The deficits can be found in several areas of cognitive functions that elderly with dementia suffer amnesia, aphasia, apraxia, and agnosia [10]. This gradual decline in function eventually creates the need for extra support in daily life. People living with dementia can experience mood changes that can be influenced by their surroundings. Normally, about $10-15 \%$ of people gradually develop dementia each year, but the rate of cognitive decline varies from person to person. Although there are ergonomic games for elderly such as "the Chitchatters" game aimed for dementia therapy, there are still many elderly suffer from progressive degenerating results in delirium and inability to function, and can terminate in death in severe cases $[16,19]$. This research aims to design innovative and sustainable product design that targets for Asian dementia population.

\section{Co-Designed Intervention with Multiple Sectors and Stakeholders}

Since 1970s, action research already played a significant role in Scandinavian participatory design projects leading social researchers to follow the guiding principles [20]. Local accountability is crucial in the research finding that social and design researchers must be geared with the local needs contributing to the knowledge pool and to serve as a stimulus to later research to produce reflective design research intervention. The investigation aimed to collect, organize, improve the existing design and its operation so as to accumulate knowledge in the participatory design process. Design intelligence offered a new and distinctive view from scholarly and scientific approaches contributing a greater influence in understanding design 


\section{Ergonomics International Journal}

research [21]. Participation design or co-design is driven by social interaction as users and designers work together to create, propose and develop their ideas together [22]. The evaluation of possible ideas and insights play a crucial role in this co-design process and has a strong focus on how co-design can reveal unforeseen opportunities and desirable possibilities. Therefore, codesign is an approach that involves all stakeholders in the collective action of creativity, understanding and mutual learning opportunity among participants offering constructive solutions in terms of products, services and systems. Participatory designers would involve other experts in their relevant domain and stakeholders facilitating the research process, contributing to the actual development of research outcomes. The co-produced outputs possess its value contributing on the professionalism of the workforce as well as their wider needs. It is an approach of designing focused on participation that consider "user as partner" rather than "user as subject" [23]. A number of key attributes are involved that differ greatly from other typical design methods, producing tangible design ideas through making process that design insights are gained, and the collaborative design experience is obtained addressing the unmet and unrecognized needs [24]. The shared decision making in co-design allows shared goals to be executed benefiting every participant when they worked together to make possible improvement.

To address the societal issue of the escalating number of dementia among the ageing population, some designers have tried to contribute innovative solutions to the healthcare sector [25]. To genuinely meet the needs of end users in dementia cases, co-design was the key to engage people with dementia in the design process [26]. Co-design combines the perspectives, input and skills of people from different backgrounds to address a specific problem [27]. Though an experimental research conducted by Mitchell, et al. [27], it was found that the codesign groups generated significantly higher number of innovative ideas than non-co- design groups. Their finding suggested that designers could create more innovative ideas if they co-design with people from various backgrounds. Perceiving the rapid ageing population as positive access of the society, Rodgers employed disruptive design interventions to co-design with people with dementia to create a new tartan. Despite being diagnosed as having dementia, those participants provided significant contributions in his co-design project in terms of creativity, working experience, skills of weaving and knowledge of the society. Rodgers' co-design project helped people with dementia keep connected to their communities and the process has improved their psychological well-being tremendously which was reflected in his research finding that those participants demonstrated delay in the needs for formal health care support. His project demonstrated the values of co-design philosophy through action. These dementia patients' improvement and independent thinking are further supported by another project by Escalante, et al. [6], which showed favourable influence on social interaction of people with dementia through co-designing digital games by having people with dementia contributing independent ideas based on real-life experiences to improve the practicality of end products. Samantha Porter and J Mark Porter [28] stressed the importance of input of ergonomics information at appropriate form in the design process to ensure function, reliability and safety.

Although a number of research shows that codesigning with people with dementia could be beneficial, the communication with dementia participants has proven to be limiting since the cognitive functions would have progressively declined in later stages of dementia $[6,25,29,30]$. Hendriks, Truyen and Duval [10] argued that traditional participatory design methods anticipated elderly who participated in design process were cognitively capable since some members in the design team might not be fully aware of the stages of dementia. Smeenk, Sturm and Eggen [14] realised that co-designing products with people with dementia could be challenging because of the communication impairment at the latter stage. They employed a case study research design to evaluate their co-design activities with multidisciplinary design teams of helping professionals and their findings have provided insight to this study. To fully address the needs of people with dementia, Smeenk, Sturm, and Eggen [14] incorporated psychological concept of empathy to develop an empathic co-design framework with three sequential co-design activities to facilitate designers' understanding of dementia - 1) individual harvest meeting; 2) collective handover workshops; and 3) empathic ideation workshops. This philosophy provides a timely and relevant model for this study and this paper will adapt a similar empathic co-design framework with slight modifications to suite the target study group in Hong Kong demography. Based on Smeenk's framework, the new version of empathic co-design process focuses on 1) individual observation sessions; 2) collective participatory co-design workshops and 3) empathic product design development workshops (Table 1). This co-design framework is applied to the various stages of co- design in this research development of a new series of ten training board games for elderly with dementia. Aside 


\section{Ergonomics International Journal}

from the dementia stakeholders, the research is supported by a multidisciplinary design team which involves dementia elderly, helping professionals and designers to research and develop this series of ten training board games in three distinctive steps which are explained in the following section.

\begin{tabular}{|c|c|c|c|}
\hline & Step 1 & Step 2 & Step 3 \\
\hline $\begin{array}{c}\text { Smeenk, et al. [14] concept of empathy } \\
\text { (2017) to develop an empathic co- } \\
\text { design framework }\end{array}$ & $\begin{array}{l}\text { individual harvest } \\
\text { meeting }\end{array}$ & $\begin{array}{l}\text { Collective handover } \\
\text { workshops }\end{array}$ & $\begin{array}{l}\text { empathic ideation } \\
\text { workshops }\end{array}$ \\
\hline $\begin{array}{l}\text { New research framework based } \\
\text { adapted from Smeenk, et al. [14] }\end{array}$ & $\begin{array}{c}\text { individual } \\
\text { observation sessions }\end{array}$ & $\begin{array}{c}\text { collective participatory design } \\
\text { workshops }\end{array}$ & $\begin{array}{l}\text { empathic product } \\
\text { design development } \\
\text { workshops }\end{array}$ \\
\hline
\end{tabular}

Table 1: Comparison between Smeenk, et al. concept of empathy (2017) and newly adapted research framework to develop an empathic co-design of a new series of training board games with elderly with dementia and multidisciplinary design team.

\section{Stage 1: Designing Ergonomic Training Games}

Step 1: Observation and semi-structure interview: To echo Smeenk, et al. [14] notion of individual harvest meeting, this research adapts a more rigorous individual observation sessions and semi-structured interviews with elders with dementia whereby a multidisciplinary codesign team was formed by involving a group of dementia participants, health care occupational therapists, social workers, local elderly centre assistants, product design professionals, design teachers and students to study and critique existing sets of elderly health care games that the dementia patients are exposed through observation and semi-structured interviews, themes were developed to understand the needs and everyday challenges of elderly with dementia for studying the game sets in the market. First and foremost, six cognitive functions have been identified as a result of desktop research and first-hand experience with dementia patients (Figure 1).

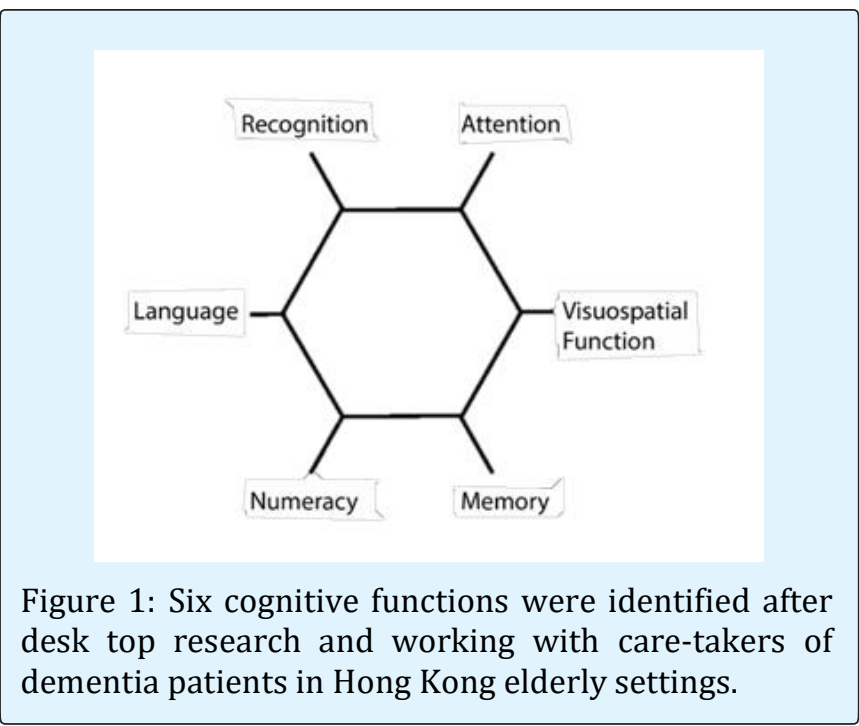

Tris KEE. Impact of Sustainable Product Design on Elderly Ergonomics. Ergonomics Int J 2018, 2(4): 000168.
Method: Observation-The essential start to understand end users' ergonomics: First, the team has made the in-depth observation sessions in dementia elderly interacting with existing sets of game sets available in the market. During the observational stage, two product designers and two graphic designers were involved and they summarised five major aspects that could facilitate the current co-design project. By understanding the needs of elderly, the designers communicated with the elderly to learn their stories and to understand their background, habits and preferences. Subsequently, some major challenges that the elderly encountered while old sets of training games in the market were identified; such as inability to grasp the full potential of the games, poor content, weak colour contrast, and illegible text size. The designers designed pilot games and tested that the Asian context were rather popular among the elderly because those games provided a lot of conversational opportunities for the elderly and offered a better understanding of their lives and interests. The co-designed pilot sets were appraised with multiple stakeholders including design students, elderly and nondesigners and it was found that elderly involvement in the co-design project was helpful to have immediate feedback on both the ergonomics and usefulness of the games. Moreover, working with design students was inspirational because they could think of innovative ideas. Nevertheless, there were also challenges during the codesign process which was rather time-consuming and led to high production costs. Also, as design students were inexperienced, some of the ideas given by them were not practical when it came to execution.

Method: Semi-structured interviews: Building on the earlier observation, a few sessions of semi-structured interviews with elderly with dementia were initiated by occupational therapist to understand the needs and 


\section{Ergonomics International Journal}

everyday challenges of elderly with dementia. Individual interviews were arranged at the service centre where elderly were familiar with to provide them a sense of safety. To protect elderly from any potential stress, data saturation was applied and each interview lasted no more than 30 minutes that occupational therapist paid attention to any signs of fatigue [2,31]. Interview data were transcribed verbatim from digital recording and subjected to thematic analysis [32]. Data were reviewed and coded by two coders that one has design background and the other has psychology background. The two coders independently identified codes and grouped into themes, then compared the themes. Discrepancies were discussed and resolved among the two coders $[11,33]$.

Findings and discussion: The semi-structured interviews were designed to collect qualitative data for indepth understanding. The following are excerpts and summaries indicating two main themes related to elderly major concerns in: 1) cognitive functions and ergonomics improvement; and 2) reminiscence of cultural identity. These themes and incorporated subthemes form the key discussions and findings to the outcome of the training board games in the following sections (Table 2).

\begin{tabular}{|c|c|}
\hline Themes & Subthemes \\
\hline \multirow{4}{*}{$\begin{array}{c}\text { Cognitive functions } \\
\text { improvement }\end{array}$} & Memory \\
\cline { 2 - 2 } & Numeracy \\
\cline { 2 - 2 } & \begin{tabular}{c} 
Recognition \\
\cline { 2 - 2 }
\end{tabular} \\
\cline { 2 - 2 } $\begin{array}{c}\text { Reminiscence of cultural } \\
\text { identity }\end{array}$ & Lanility \\
\cline { 2 - 2 } & The good old days \\
\hline
\end{tabular}

Table 2: Themes and subthemes from interviews with elderly.

\section{- Cognitive Functions and Ergonomics Improvement}

Elderly felt their cognitive functions had been declining that affected their everyday life. They were happy to go to the centre to have training in cognitive functions that they could go on their daily routine, for instance, to go shopping and object recognition.

Memory: Due to memory loss, they worried about missing or exceeding the recommended medicine dosage. Moreover, they were afraid of getting lost if they went out alone. Therefore, they only went to places that were necessary, for instance, going to the elderly centre or nearby wet markets. Elderly A said, 'Besides buying groceries for cooking, I do not go out much'.

Numeracy: Elderly preferred cooking at home to eating out, they found that the training they received at the centre for counting and calculating small change was helpful for them to do the shopping. Elderly B said, 'sometimes counting things, other times using fingers'. As elderly showed concern about being taken in at the markets; therefore, they welcomed more training in numeracy.

Recognition: Some elderly had difficulties in finding correct items at home or during shopping because they easily got confused between objects. Although there was training for words recognition provided by the centre, they were also interested in object recognition.

Attention and visuospatial ability: Elderly A found herself getting clumsier with age. She attributed the reason to vision deterioration but she did not find any serious problem with her eyesight. She said, '(I) participate in drawing to have more training'. Although she was not able to use the scientific terminology of attention and visuospatial ability, the existing training sessions included some activities to maintain these two cognitive functions of elderly.

Language: At the centre, elderly were encouraged to practice language acquisition to have everyday conversation with each other to develop bonding and harmonic environment. The helping professional at the centre especially raised topics of food, cooking and good old days to gain elderly's attention and engage them in conversation. For instance, Elderly B said, '(I) prefer those which are related to food'.

\section{- Reminiscence of Cultural Identity}

Another key finding related to Asian dementia demography is the importance of reminiscence as Asian cultural identity and authentic collective memory have been acknowledged by the elderly as something they treasure dearly. Some of the key findings are:

Reminiscing their good old days: While talking about involving new activities in the centre, elderly demonstrated either lack of interest or dislike of trying new things because they expected they could not acquire new skills. On the other hand, they were vigorously engaged in the conversation about their youth and sharing personal occurrences, which were like a return to the good old days of their generation. They displayed their interest if any new activities could stimulate reminiscing to their past experience and youth memory.

Cultural identity: Another topic that could spark active conversation was Yum Cha - a traditional Chinese tea breakfast in a restaurant which was a popular activity among elderly. Besides remember delicious Chinese Dim 


\section{Ergonomics International Journal}

Sum food, elderly perceived going to Chinese restaurant Yum Cha was a dear Chinese tradition that brought back fond memories.

\section{- Compare and Contrast Elderly Game Sets in the Market}

The findings of interviews of elderly provided a practical foundation to compare and contrast games sets in the market. Major design shortfalls were identified with the available game sets in the market were lack of tactile quality, weak colour differentiation,

Invisible font sizes: Lack of cultural identity, and lack of association in context and graphics as well as unattractive visual quality that are the factors hindering any full engagement of Asian elderly with the game sets. Many of the participants agreed that there are currently a shortage of game sets in the market where local elderly can feel at ease in associating with their own cultural identity, societal context and childhood memory. As a result, the team has been aspired to focus on a reminiscence approach of training board games in the Stage 2, Participatory Co-design.

\section{Step 2: Participatory co-design-reminiscence approach of training board games}

Supported by the observation in Step 1, the collective participatory design process started in May 2016 to December 2017 in co-designing with the full team of elderly, helping professionals such as care-takers, social workers, occupational therapists as well as product designers, graphic designers, academia and design students. The process entailed multiple attempts in backand-forth trials of testing and redesigning. The elderly stakeholders have provided endless amount of feedback in the wish to have some Asian context design that elderly living with dementia can easily identify, feel at home and be able to take more control in ownership in their training games.

Previous studies on training games designed some computer-based games for training cognitive functions of elderly with dementia. For example, Thompson, et al. [34] developed a computer-based board game to train different cognitive functions for participants who were in early stage of cognitive impairment. To train prospective memory, daily events, such as remembering to take medication, popped up on the screen after participants rolled the dice on the computer. To train decision making, the daily events, for instance, having lunch at a café, popped up to require participants' decision to place order in the café. Their findings showed that, after training for eight times, the magnitude of deficit in prospective memory was reduced but significant impairment remained. Although their findings suggested that the computer-based board games could be useful in training cognitive functions of elderly with dementia, this paper argues that cultural differences are a potential concern. Those daily events in the study conducted by Thompson, et al. [34] were developed based on Western society that might not be suitable among Hong Kong population. Since Hong Kong elderly would rather enjoy Dim Sum at Chinese restaurant than go to café, the unfamiliar events and objects in training games may affect the training outcome. Especially, as mentioned above, the cognitive impairment impedes the working memory for learning new concept among elderly with dementia [19]. Due to the cultural differences, training game sets designed for Hong Kong ageing population is essential. However, there is insufficient research in Hong Kong to cope with the demographic shift to a more elderly population [9].

By understanding the nature of dementia that the long-term memory often still functions even at later stages [19], Luckner, et al. [35] applied the therapeutic approach of reminiscence to their co-design project. Reminiscence refers to the cognitive process of recalling experiences from the past [15]. Luckner, et al. [35] codesigned with elderly with dementia, their family members, and helping professionals to develop computerbased games with video images to trigger reminiscence to ameliorate elderly's memory loss. To activate participants' reminiscence, personalised databased of video clips, pictures, music and similar objects were developed. Although using computer application could be cost-effective to set up personalised databased with bespoke materials for different elderly, there was a major limitation in their research that computer-based games may not be helpful in triggering reminiscence. Computer use could be relatively abstract for elderly, especially among Hong Kong elderly, since computers were not prevalent among their generation. Therefore, the training games could be designed consistent with familiar objects and everyday experiences to trigger the collective memory of elderly. As mentioned in their research, there was a common belief that playing and cognitive training should be separated [35].

\section{Step 3: Empathic product design development workshops \\ Collaborated between a local elderly dementia centre in Hong Kong, a graphic design company and the Product Design Faculty in the Technological and Higher Education Institute of Hong Kong, a series of ten sets of training board games were developed to alleviate the}




\section{Ergonomics International Journal}

deterioration in cognitive decline, behavioural changes and functional limitations of elderly with dementia through imagination and social interaction.

Table 3 illustrates the details of each set, the objective in the cognitive training and how they utilize reminiscence approach in bring the cultural context by bringing familiar objects and events such as local context, old transportation images, Asian food, Hong Kong typical high density residential environment, an typical Asian elderly's daily schedule, and a money management system that is familiar to Hong Kong elderly. The design team has tested the game sets to multiple elderly settings including over 50 elderly at the Caritas Aberdeen Community Center.

\begin{tabular}{|c|c|c|}
\hline $\begin{array}{c}\text { Name of the new } \\
\text { game }\end{array}$ & Design Description & $\begin{array}{l}\text { Area of Training related to } \\
\text { Ergonomics and Cognition }\end{array}$ \\
\hline The Old and New & $\begin{array}{l}\text { To stimulate memory through those photos in the past and present } \\
\text { and to identify the differences with verbal communication. }\end{array}$ & Memory and Language \\
\hline My Schedule & $\begin{array}{l}\text { To work out a daily schedule plan with participants and to explore } \\
\text { the rationale of their decision though in-depth discussion. }\end{array}$ & Memory and Language \\
\hline Dot Linking & $\begin{array}{c}\text { To imitate the given diagram and to identify the separate shapes } \\
\text { through line drawing. }\end{array}$ & $\begin{array}{l}\text { Attention and Visuospatial } \\
\text { function }\end{array}$ \\
\hline Shape Matching & $\begin{array}{c}\text { To concentrate and identify the correct symbol among the others } \\
\text { through color and shape recognition. }\end{array}$ & Attention and Recognition \\
\hline $\begin{array}{c}\text { Money } \\
\text { Management }\end{array}$ & $\begin{array}{l}\text { To recognize the local currency through purchase simulation and to } \\
\text { memorize the goods being purchased and discuss further } \\
\text { facilitator. }\end{array}$ & Numeracy and Memory \\
\hline Numerical Bingo & $\begin{array}{c}\text { To answer the simple mathematics through calculation and identify } \\
\text { the correct answer with a physical pointer. }\end{array}$ & Numeracy and Attention \\
\hline Shape Chess & $\begin{array}{c}\text { To memorize the exact location of the objects and rearrange them on } \\
\text { the same place after certain period of time. }\end{array}$ & $\begin{array}{l}\text { Visuospatial function and } \\
\text { Memory }\end{array}$ \\
\hline Number Tangram & $\begin{array}{l}\text { To locate the corresponding physical Tangram back to its original } \\
\text { position. }\end{array}$ & $\begin{array}{l}\text { Visuospatial function and } \\
\text { Attention }\end{array}$ \\
\hline Object Placement & $\begin{array}{l}\text { To identify the objects usually appeared in living areas and arrange } \\
\text { them back to the corresponding locations on a piece of on magnetic } \\
\text { mat, followed by sharing discussion }\end{array}$ & Recognition and Language \\
\hline Dim Sum Game & $\begin{array}{l}\text { To take turn and match the image of similar dim sum card and } \\
\text { discuss with their past experience on dining outside. }\end{array}$ & Recognition and Language \\
\hline
\end{tabular}

Table 3: List of the 10 sets of training board games and their training foci.

\section{Stage 2: Focus Group Interview}

To understand how the co-design process in this research could achieve the beneficial outcome of the training board games among Hong Kong ageing population. Focus group interviews were conducted and thematic analysis was employed to identify themes. As focus group is designed for in-depth group interviews with purposively selected participants to discuss on a given topic, this technique is implemented in this research to generate deeper and richer data through social interaction between participants and moderators [36].

Method: A focus group interview lasted for around 75 minutes, with eight participants who had experience working with elderly including designers, academia, social workers, occupational therapists, occupational therapist assistants, and two moderators. Data saturation was applied and interview data were transcribed verbatim from digital recording and subjected to thematic analysis [32]. Also, data were reviewed and coded by two coders that one has design background and the other has psychology background. The two coders independently identified codes and grouped into themes, then compared the themes. Discrepancies were discussed and resolved among the two coders $[11,33]$.

Findings and discussion: The focus group interview were designed to collect large amount of qualitative data in a comparatively shorter time frame to in-depth understand the beneficial outcome of the training board games through group dynamic [36]. The current findings indicated four main themes; 1) objectives achieved; 2) 


\section{Ergonomics International Journal}

participant engagement; 3) benefits and strengths; and 4) challenges and limitations. These themes and incorporated subthemes, shown in Table 4, contribute to understand the outcome of the training board games and their impact.

\begin{tabular}{|c|c|}
\hline Themes & Subthemes \\
\hline \multirow{4}{*}{$\begin{array}{l}\text { Objectives } \\
\text { achieved }\end{array}$} & Clear instructions \\
\hline & Texture \\
\hline & Aesthetics \\
\hline & Reminiscence of cultural identity \\
\hline \multirow{3}{*}{$\begin{array}{l}\text { Participant } \\
\text { engagement }\end{array}$} & Stimulation \\
\hline & Motivation \\
\hline & Communication \\
\hline \multirow{4}{*}{$\begin{array}{l}\text { Benefits and } \\
\text { strengths }\end{array}$} & $\begin{array}{c}\text { Cognitive functions in } 6 \text { domains: } \\
\text { numeracy, language, money, recognition, } \\
\text { visuospatial function }\end{array}$ \\
\hline & Social: interaction, cultural specific \\
\hline & Materials: durable, presentable \\
\hline & Integration \\
\hline \multirow{3}{*}{$\begin{array}{c}\text { Challenges and } \\
\text { limitations }\end{array}$} & Font Size \\
\hline & Compact Packaging \\
\hline & $\begin{array}{c}\text { Separated for individual and group } \\
\text { training }\end{array}$ \\
\hline
\end{tabular}

Table 4: Themes and subthemes from focus group interviews

\section{- Objectives achieved}

The research findings in Stage 1 of the current research contributed to the development of the ten sets of training board games which aims to delay the deterioration of cognitive functions of elderly with dementia in six domains; namely memory, language, recognition, visuospatial function, numeracy and attention. During the focus group interview, the objectives of the current project were first clarified for evaluation of the outcomes.

Clear instructions: Although instructions had already been included in the existing game sets for training cognitive functions of elderly with dementia, the newly designed game sets with systematic and organised instructions that could demystify any new service providers to easy pick up the training systems and techniques that increased the efficiency. Social worker A said, 'After demonstration of the training game sets, some other non-government organisations was amazed at the clarity of the training objectives of showing three levels of training in six cognitive functions.'

Texture: From the perspective of the occupational therapist, the better tactile quality of the new developed board games was useful in training elderly to stimulate their kinaesthetic sensations that matched with the paradigm of integrating multi-sensory stimulation into training [37]. Occupational therapist A mentioned, 'an occupational therapist from another organisation shows the admiration of our game sets that, besides using cardboard, elderly can physically touch the accessories of the games made with different materials.'

Aesthetics: The training games sets were co-designed with a group of health professionals to ensure the professional standard. However, some materials might be cost-effective; but we're not be suitable for producing the game sets, for example thin paper or glossy printing. As the newly developed game sets improved those drawbacks to use colour and presentable features that could draw elderly's attention, these game sets could achieve both functional and aesthetically pleasing.

Reminiscence of cultural identity: According to the findings in Stage 1, elderly demonstrated their penchant for the good old days and Chinese style Yum Cha. The themes of reminiscence and cultural elements incorporated in the design of the game sets that could successfully enhance elderly's willingness to engage in the training. For example, while training the cognitive function of recognition, elderly showed their interests in differentiating between old and new objects hinging on their past that encouraged communication. Occupational therapist B said, 'the reminiscent design based on cultural context brings elderly back to their past to help them concentrate on the recognition task.' As there is rather unusual to find Chinese cognitive training games in foreign countries, the cultural specific elements attracted some overseas elderly organisations which serve Chinese communities to find this game set useful.

\section{- Participant engagement}

Besides aesthetically pleasing, the colourful features and tactile quality of the newly designed game sets could successfully engage elderly's interest while training.

Stimulation: Colour could be a common topic to spur the conversation with elderly. In the paper written by Hendriks, Truyen and Duval [10], they demonstrated how to engage a woman with dementia in a conversation of colours, such as, the preferred and unwanted colours of her belongings. In the current research, colour themes and three- dimensional accessories of the game sets were designed to stimulate elderly's visual and kinaesthetic sensations. Social worker A said, 'the elements of the game, named Bingo, provide an opportunity for elderly to recognise colours and positions. Elderly enjoy playing with the accessories as if they were playing chess.' Also, the objects in the photos were especially selected with cultural consideration to attract elderly's attention and to stimulate them to think. 


\section{Ergonomics International Journal}

Motivation: With the integration of cultural elements, such as Dim Sum and familiar objects, the game sets were well-received. One of the best designs of the current game sets was the manufactured materials selection. For example, the above mentioned Bingo was made from magnetic board that elderly could feel the magnetic force when they placed the chess on the right spot. It gave elderly the feeling of instant feedback to motivate elderly to go on playing with the games. Social worker B said, 'the magnetic force sends instant physical feedback to elderly, which they can feel it by themselves, giving them motivation.'

Communication: Elderly were more willing to communicate when they saw familiar objects, which could triggered their memories of the past and their own histories, such as the evolving of transportations. The reminiscence played a major role in fostering communication, for example, occupational therapist assistant A said, 'when an elderly told me there should be an older version of the train than the one shown on the photo, I asked him to tell me more about it. He felt encouraged, and then was willing to communicate more.'

\section{- Benefits and strengths}

The ten sets of training board games were well-received from two perspectives: design and practical training point of view. The improved colour and quality improved usability, tactile quality and ergonomic factors which are essential to a set of good design. On the other hand, the use of reminiscence training and cultural references have given this set of games strength and uniqueness in codesign realm. The game sets provided extended favourable outcomes other than the achieved objectives and have successfully reached outside of Hong Kong to impact other communities with Chinese population. Some of the strengths can be identified as:

Cognitive functions: The game sets were designed to delay the deterioration of cognitive functions of elderly with dementia in six domains; namely memory, language, recognition, visuospatial function, numeracy and attention. By observation, it is believed that the game sets could overall facilitate the training of the six domains among elderly. As mentioned above, the reminiscence approach helped sustain elderly's attention, stimulate their thinking and enhance their willingness to communicate. For example, occupational therapist B said, 'elderly are more engaged when talking about childhood life events that facilitate their language acquisition.' Besides, the training game of timetable, named My Schedule, trained not only language but also memory with hands- on activities. As mentioned in the findings of Stage 1 , some elderly concerned about calculating small change while doing the shopping at the market. Money Management could address their apprehension to train them memory as well as numeracy.

Social: During the group training session at the elderly service centre, the elements of game sets provided a common topic for elderly to discuss with. For example, while training the game set, named Object Placement, the household accessories in the game created an opportunity for elderly to share their personal experience with others. Social worker B said, 'when they (elderly) share their experience, the interaction between them become obvious.'

Materials: At service centre, it was usual that training materials were used in everyday basis; therefore, durable materials should be used to manufacture the game sets. The newly designed training board games in the current project were especially developed to address this characteristic.

Integration: The multidimensional elements made the game sets easily integrate with other training activities, such as orientation during the warm up session, to train a group of cognitive functions at the same time. For example, the images in the game set, named Money Management, included groceries and other household products to provide training of numeracy together with recognition of objects.

\section{- Challenges and limitations}

The game sets also face many limitations. Some of the suggestions of improvement have been made by health professionals after training sessions are:

Sizes of fonts, images and accessories: As elderly's vision changes with age, the sizes of fonts and images may have to further adjust to address their problem. Although the scales of real-objects were preserved while developing the game sets, some kitchenware on the images were too tiny for elderly recognise during training. Also, some accessories of the board games, such as plastic circles in the Shape Matching game, were relatively small for elderly to pick up.

Compact packaging: Although the magnetic force of the game Bingo could give elderly physical feedback as motivation, the force was too strong for some elderly to control the magnetic chess. The packaging of the magnets may have to improve to prevent them from sticking together. Another limitation of the packaging was that they were too bulky for storage at elderly centre and too heavy for home visit. A more compact design of the packaging would be welcomed.

Separated for Individual and Group Training: Although the game sets were divided for individual and group training, the separation was not clear. A suggestion 
was made by occupational therapist assistant B that more elements to facilitate the interaction between elderly were needed in group training game sets.

\section{General Discussion and Conclusion on the Sustainability of Co-Designed Game Sets for Elderly}

The current paper entailed multiple stages of research, design and development. It has gone through a long period of assessment, testing and evaluation of the design and ergonomics. In conclusion, it included a back-andforth co-design development and practical evaluation of this new series of ten board games to train cognitive and ergonomic functions among elderly with dementia. As Luckner, et al. [35] suggested, a demand for cognitive training set with playful elements was needed in the market to encourage elderly's motivation to participate in the training. Although those researchers' emphasised games with personalised elements could enhance elderly's engagement in bespoke training and occupational ergonomics, his concept did not match Hong Kong collectivistic culture. This research pro- actively addressed this concern by applying psychological therapeutic approach of reminiscence to the new game sets to trigger collective memories and cultural identity for a specific Aisan elderly population (Figure 2) [15].

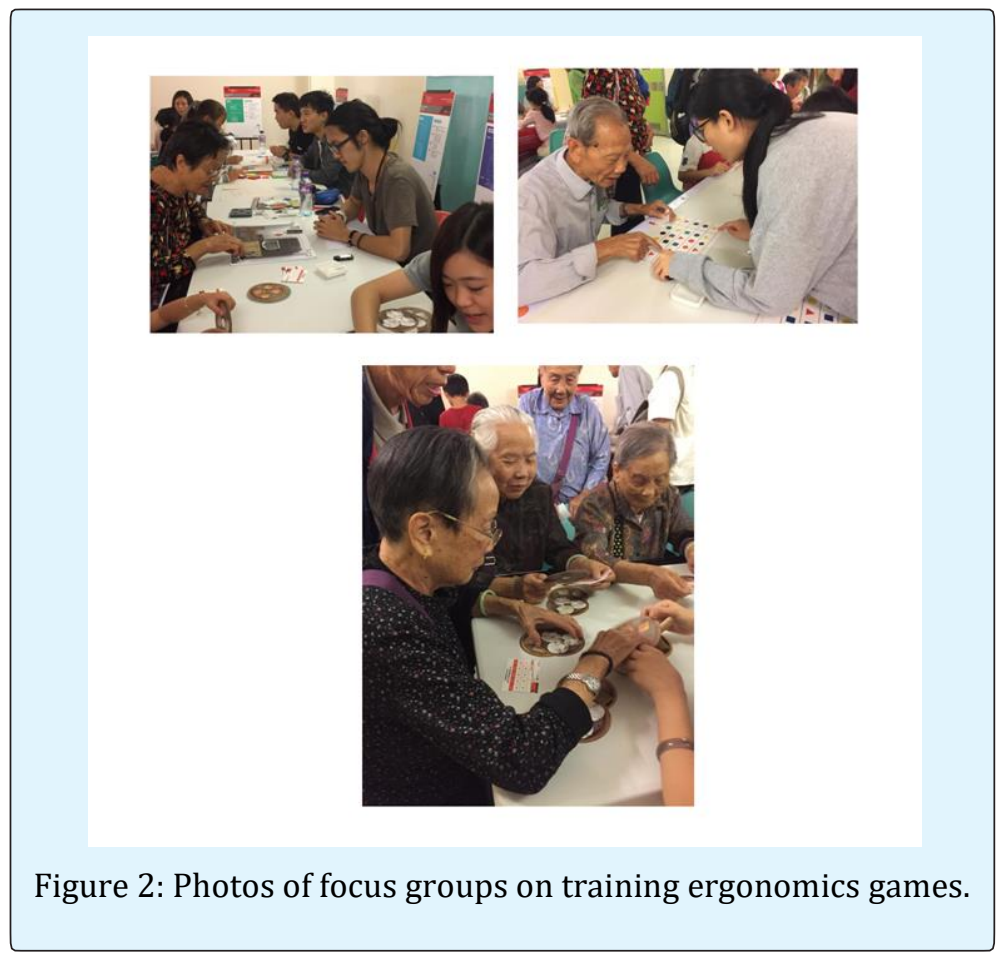

The focus group interview gave further insight into the meanings, beliefs, cultures and participants' feelings, attitudes and behaviours for the evaluation of healthrelated intervention [36]. The findings of the focus group interview supported the hypothesis that game sets with reminiscence elements was effective to stimulate elderly's cognitive functions in terms of memory, recognition, language acquisition and social interaction. The current findings also showed that improved tactile quality and aesthetic characteristics could successfully retain elderly's attention longer while training outcome benefited. Besides, the materials of the newly designed game sets were co-designed with professionals and stakeholders, generating the most relevant design outcome. However, the major limitations of the research such as time constraints, human resources and the small number of participating elderly can be room for future research. Some shortcomings of the design was discovered such as sizes of fonts, images and accessories should be further adjusted to focus on the cognitive and physical deterioration among elderly with dementia.

Our world is confronted with an unprecedented figure of ageing elderly with dementia globally, with a soaring number estimated to multiply by 60 percent in 2030 [1], this urges an immediate demand in addressing this society problem in all fronts, including the design disciplines. Therefore, the current paper focuses on the 


\section{Ergonomics International Journal}

development of interactive board games to train cognitive functions of elderly with dementia with a specific demographic cohort. The research not only offers deeper understanding of the performance of elderly games in a co-design perspective, but also the critical elements of codesign in health care products as it offers beneficial outcomes and generated a sustainable and user-oriented design that has a positive impact to our ageing population.

\section{Acknowledgements}

The authors wish to gratefully acknowledge the Technological and Higher Education Institute of Hong Kong in funding support of the current project. In addition, the authors would like to express the deepest gratitude to elderly and care-takers for their participation and openly sharing their first-hand experiences, and to thank Christian Family Service Centre (CFSC) Mind delight Memory \& Cognitive Training Centre and Co-LAB for their professional advice and support over the whole project.

This paper is supported by RGC-IDS Project No. UGC/IDS25/16 entitled "Research on Sustainable Living: Phase Two of the Capacity Building Plan"

\section{Disclosure Statement}

No potential conflict of interest was reported by the authors.

\section{Funding}

This work was supported by the Technological and Higher Education Institute of Hong Kong under Seed Grant number SG1617112.

\section{References}

1. WHO (2017) 10 facts on dementia. World Health Organization.

2. Wong Gloria HY, Olive PL Yek, Anna Y Zhang, Terry YS Lum, Aimee Spector (2018) Cultural adaptation of cognitive stimulation therapy (CST) for Chinese people with dementia: multicentre pilot study. International journal of geriatric psychiatry 33(6): 841-848.

3. Backman L, Jones S, Berger AK, Laukka EJ, Small BJ (2005) Cognitive impairment in preclinical

Tris KEE. Impact of Sustainable Product Design on Elderly Ergonomics. Ergonomics Int J 2018, 2(4): 000168.
Alzheimer's disease: a meta-analysis. Neuropsychology 19(4): 520-531.

4. Lee Danny, Selina Cheah (2016) Hong Kong Women and Men Enjoy World's Longest Life Expectancy due to Low Smoking Rates, Health Experts Claim. South China Morning Post.

5. Branco Rita, Joana Quental, Óscar Ribeiro (2015) Getting Closer, Empathising and Understanding: Setting the Stage for a Co-design Project with People with Dementia. IxD\&A 26: 114-131.

6. Escalante, Maria A Luján, Emmanuel Tsekleves, Amanda Bingley, Adrian Gradinar (2017) 'Ageing Playfully': a story of forgetting and remembering. Design for Health 1(1): 134-145.

7. Mshali Haider, Tayeb Lemlouma, Maria Moloney, Damien Magoni (2018) A survey on health monitoring systems for health smart homes. International Journal of Industrial Ergonomics 66: 2656.

8. Rodgers Paul A (2017) Co-designing with people living with dementia. CoDesign 14(3): 1- 15.

9. Liauw, Laurence, Shum R, Wong H, OL Lo (2001) Elderly care residential typologies: comparative case studies between Hong Kong \& international facilities and industry trends: School of Design. Hong Kong Polytechnic University, Hong Kong.

10. Hendriks Niels, Frederik Truyen, Erik Duval (2013) Designing with dementia: Guidelines for participatory design together with persons with dementia. IFIP Conference on Human-Computer Interaction, pp: 649-399.

11. Lindsay Stephen, Katie Brittain, Daniel Jackson, Cassim Ladha, Karim Ladha, et al. (2012) Empathy, participatory design and people with dementia. Proceedings of the SIGCHI Conference on Human Factors in Computing Systems.

12. Broberg Ole (1997) Integrating ergonomics into the product development process. International Journal of Industrial Ergonomics 19(4): 317-327.

13. Gallogly Carolyn Marie (2009) Spousal Identity Stage Theory in Dementia Caregiving A Bittersweet Journey. The Graduate School, Stony Brook University: Stony Brook, NY. 


\section{Ergonomics International Journal}

14. Smeenk Wina, Janienke Sturm, Berry Eggen (2017) Empathic handover: how would you feel? Handing over dementia experiences and feelings in empathic co-design. CoDesign 13(2): 1-16.

15. Okumura Yumiko, Satoshi Tanimukai, Takashi Asada (2008) Effects of short- term reminiscence therapy on elderly with dementia: A comparison with everyday conversation approaches. Psychogeriatrics 8(3): 124133.

16. Butcher, James Neal, Susan Mineka, Jill M Hooley (2013) Abnormal psychology: Pearson. New York.

17. Alzheimer's Association (2016) 2016 Alzheimer's disease facts and figures. Alzheimer's \& Dementia 12(4): 459-509.

18. Kelley AS, McGarry K, Gorges R, Skinner JS (2015) The burden of health care costs for patients with dementia in the last 5 years of life. Annals of internal medicine 163(10): 729-736.

19. van Rijn H, van Hoof J, Stappers PJ (2010) Designing Leisure Products for People with Dementia: Developing "the Chitchatters" Game. Am J Alzheimers Dis Other Demen 25(1): 74-89.

20. Suchman Lucy (2002) Located accountabilities in technology production. Scandinavian journal of information systems 14(2): 91-105.

21. Cross Nigel (2001) Designerly ways of knowing: Design discipline versus design science. Design issues 17(3): 49-55.

22. Simonsen Jesper, Toni Robertson (2012) Routledge international handbook of participatory design. Routledge.

23. Sanders Elizabeth BN, Pieter Jan Stappers (2008) Cocreation and the new landscapes of design. Co-design 4(1): 5-18.

24. Hunter Mat (2014) What design is and why it matters.

25. Tan Lauren, Deborah Szebeko (2009) Co-designing for dementia: The Alzheimer 100 project. Australasian Medical Journal (Online) 12: 185-198.

26. Matthews Eric (2006) Dementia and the identity of the person.
27. Mitchell Val, Tracy Ross, Andrew May, Ruth Sims, Christopher Parker (2016) Empirical investigation of the impact of using co-design methods when generating proposals for sustainable travel solutions. Codesign 12(4): 205-220.

28. Porter CS, MARK Porter (1999) Designing for usability: Input of ergonomics information at an appropriate point, and appropriate form, in the design process. Human factors in product design, pp: 15-25.

29. Span Marijke, Marike Hettinga, Myrra VernooijDassen, Jan Eefsting, Carolien Smits (2013) Involving people with dementia in the development of supportive IT applications: a systematic review. Ageing research reviews 12(2): 535-551.

30. Cockton Gilbert (2009) Getting there: six metaprinciples and interaction design. Proceedings of the SIGCHI Conference on Human Factors in Computing Systems.

31. Hellstrom I, Nolan M, Nordenfelt L, Lundh U (2007) Ethical and methodological issues in interviewing persons with dementia. Nursing Ethics 14(5): 608619.

32. Melunsky N, Crellin N, Dudzinski E, Orrell M, Wenborn J, et al. (2015) The experience of family carers attending a joint reminiscence group with people with dementia: A thematic analysis. Dementia 14(6): 842-859.

33. Bryan CJ, Butner JE, Sinclair S, Bryan ABO, Hesse CM, et al. (2017) Predictors of emerging suicide death among military personnel on social media networks. Suicide and Life- Threatening Behavior.

34. Thompson Claire, Julie D Henry, Peter G Rendell, Adrienne Withall, Henry Brodaty (2010) Prospective memory function in mild cognitive impairment and early dementia. Journal of the International Neuropsychological Society 16(2): 318-325.

35. Luckner Naemi, Fares Kayali, Oliver Hödl, Peter Purgathofer, Geraldine Fitzpatrick, et al. (2013) From research to design-sketching a game to trigger reminiscence in older adults. In Human factors in computing and informatics, pp: 617-624.

36. Rabiee Fatemeh (2004) Focus-group interview and data analysis. Proceedings of the nutrition society 63(4): 655-660. 
37. Baker R, Holloway J, Holtkamp CC, Larsson A, Hartman LC, et al. (2003) Effects of multi-sensory stimulation for people with dementia. Journal of advanced nursing 43(5): 465-477. 